\title{
51. INTRODUCTION TO THE GUAYMAS BASIN AND HYDROTHERMAL SYMPOSIUM ${ }^{1}$
}

\author{
Joseph R. Curray and David G. Moore, Scripps Institution of Oceanography, La Jolla, California
}

\begin{abstract}
This, the second symposium of the Leg 64 Initial Reports, is a collection of papers on the principal results of drilling in the Guaymas Basin floor (Figs. 1 and 2). Two sites, Sites 477 and 481 , were drilled into active spreading axes of opening of the Gulf of California. The third site, Site 478 , was drilled in what had been interpreted to be somewhat older rocks of the basin floor. Objectives of this drilling were to test the tectonic model of formation and locus of generation of new oceanic crust, to investigate the sediments deposited in this environment, to determine the nature of the expected sediment-basalt mixtures and to explore for possible hydrothermal alteration products in this region of known high heat flow. An important secondary objective was to investigate the content and early maturation of hydrocarbons believed to occur in this region of high heat flow. Results of organic geochemistry studies were reported in the preceding collection of papers. The following papers include
\end{abstract}

\footnotetext{
${ }^{1}$ Curray, J. R., Moore, D. G., et al., Init. Repts. DSDP, 64: Washington (U.S. Govt. Printing Office).
}

petrologic, sedimentologic, and inorganic geochemical aspects of the drilling results.

At the time of occupying these sites in the Guaymas Basin in December 1978, we did not know what our drilling would encounter. No drilling had previously been done in presumed zero-age crust. Extremely high heatflow values were known in the Site 477 area, and one model calculated on the basis of these heat-flow measurements, plus study of seismic-reflection records, suggested the possibility of a magma chamber only $100 \mathrm{me}-$ ters beneath the sea floor. The possibilities of the drill encountering molten rock were, in fact, discussed at a Safety Panel review of these drilling sites, but fortunately wisdom prevailed, and no restrictions were put on these sites other than the usual hydrocarbon restrictions. The drilling in fact proved to be more exciting than anticipated because of encounters with very earlymaturated hydrocarbons, very young thermally metamorphosed sediments, and coarse-grained dolerite sills. The results of this drilling and sample analysis are summarized in the following collection of papers. 


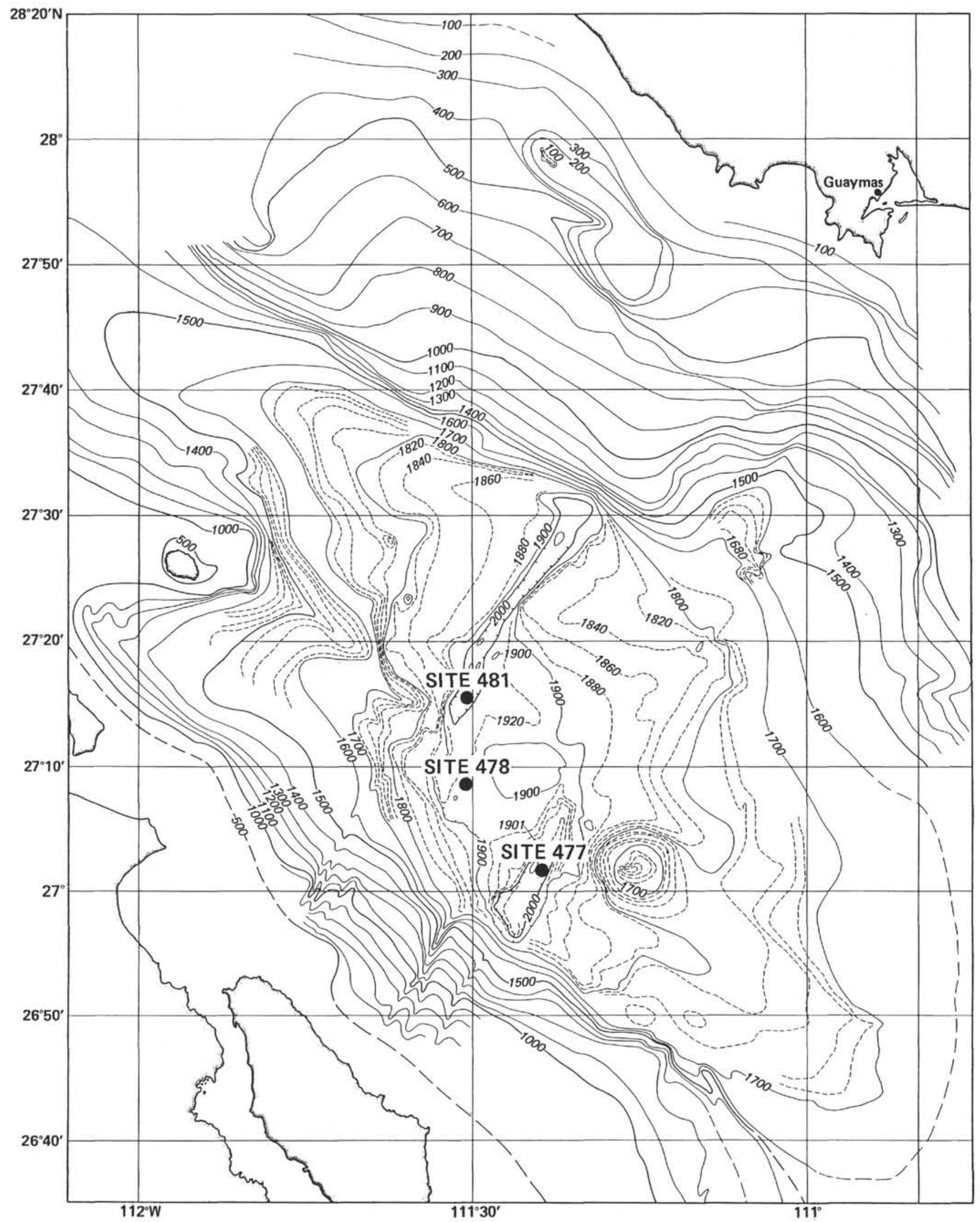

Figure 1. Bathymetry of the Guaymas Basin (modified from Sharman, 1976, by F. J. Emmel and H. E. Sheline), with drilling sites. 

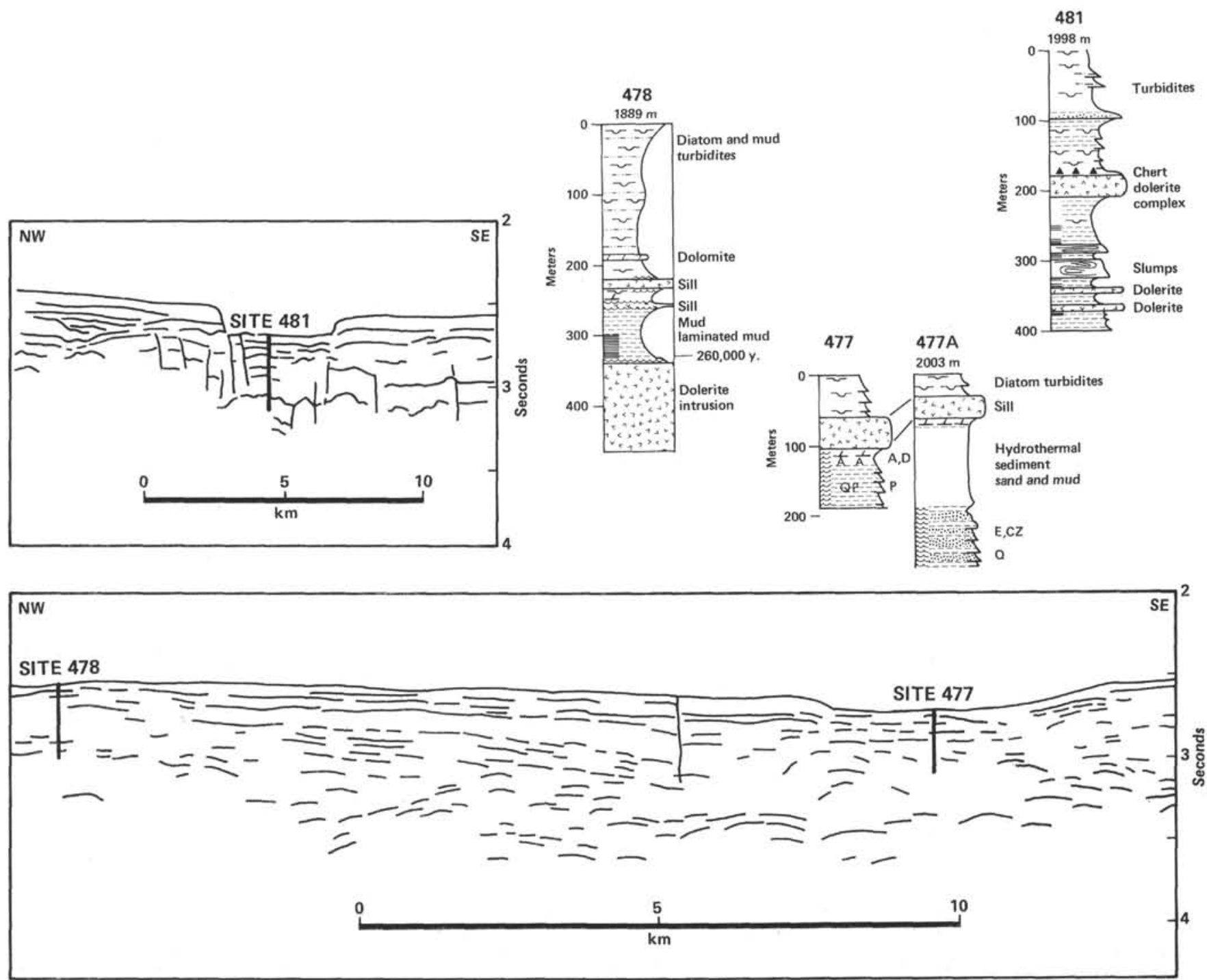

Figure 2. Simplified principal lithologic results and line drawing of seismic section through the Guaymas Basin rift transect (Symbols referring to hydrothermally formed deposits and minerals at 477 and $477 \mathrm{~A}$ are: $\mathrm{A}=$ anhydrite, $\mathrm{D}=$ dolomite, $\mathrm{E}=$ epidote, $\mathrm{C}=$ chlorite, $\mathrm{P}=$ pyrite, $\mathrm{Q}=$ quartz and $\mathrm{Z}=$ zeolites.) 